\title{
Engineering Support of Orthopedics and Rehabilitation
}

ISSN: 2637-8078

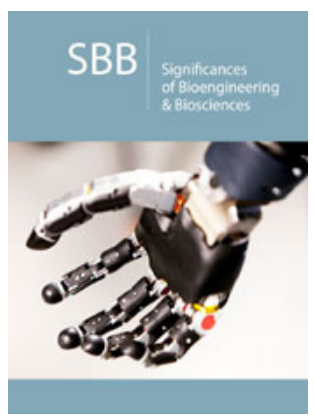

*Corresponding author: Wlodzimierz S Erdmann, Faculty of Physical Culture, Gdansk University of Physical Education and Sport, Gdansk, Poland

Submission: 眥January 26, 2021

Published: 制March 05, 2021

Volume 4 - Issue 4

How to cite this article: Wlodzimierz $S$ Erdmann. Engineering Support of Orthopedics and Rehabilitation. Significances of Bioengineering \& Biosciences .4(4). SBB. 000593. 2021. DOI: 10.31031/SBB.2021.04.000593

Copyright@ Wlodzimierz S Erdmann, This article is distributed under the terms of the Creative Commons Attribution 4.0 International License, which permits unrestricted use and redistribution provided that the original author and source are credited.

\section{Wlodzimierz S Erdmann*}

Faculty of Physical Culture, Gdansk University of Physical Education and Sport, Poland

\section{Abstract}

The article is devoted to the support by engineering to the one of medical branches, namely orthopedics and its extension, i.e., rehabilitation. Human life gives large amount of congenital disorders, victims of disasters and accidents. In order to execute surgical operation physicians need special equipment. During the operation they apply different devices in order to bring back patients as much as possible to the society. During rehabilitation process people with disabilities use many simple or advanced equipment, facilities, outdoor parks. People with disabilities need to take care of themselves. They want to participate as much as they can in many aspects of healthy members of the society. Here they are helped by simple or sophisticated devices, e.g., orthoses, implants, prostheses, wheelchairs, specially designed sport equipment. Advanced approach to people with disability was presented during "Cybathlon" competition held in Zurich in 2016, i.e., robotic prostheses for upper and lower extremities, exoskeletons and other [1].

Keywords: Engineering; Orthopedics; Rehabilitation; Orthoses; Prostheses; Implants

\section{Introduction}

Human life changes as the technology changes. There are many approaches of technology which improved human life in almost every aspect. People take care about their health, they use more convenient clothes, introduce ergonomic devices, work stands and vehicles, organize more safety environment at home, at work, during leisure time [2]. On the other hand, many people do not care about their health and safety and they are subject to many pathological states. For few hundred years humanity witnessed tremendous changes in production, services, transportation, communication and several other aspects of human life. Unfortunately, with the development of technology the number of its victims also developes. There were more industrial accidents, especially within the heavy industry and mining, more traffic accidents, more victims of fires. This fatal trend was reversed at the second half of the $20^{\text {th }}$ century since several precautions were introduced. It is not good to be overloaded, but it is also not good to be almost fully unloaded. Human body needs optimal loading. In this case muscle system could properly act against some of the sources of disability. Despite tremendous progression of the quality of human life there is enormous number of disabilities. About one billion people, or $15 \%$ of the world's population, experience some form of disability. Onefifth of them experience significant disabilities [3]. There are different sources of disabilities. Among pathological sources there are: congenital disorders, sickness, effects of accidents, disasters, wrong doings (e.g., access of eating and lack of movement that leads to obesity). There are also ontogenetic disabilities of infants and elderly people. One can say both sources of disabilities, i.e., pathological and ontogenetic constituent a quarter of world population disabled. Human race since its appearance was involved in movement. This is an indispensable aspect of life. Humans used movement for building, hunting, defence, production, transport, also for cultural activities like dancing. For a long time, engineering was involved in better production process where the amount of human physical work was diminished and in many industries was substituted by automation process and then by manipulators and robots. People were also involved in exercising which later on turned to be a sport for all or sport for the whole life. There is also a competitive approach to the movement which in modern times developed as amateur and professional sport. Here engineering was involved in obtaining better sport results and better refereeing. If there is an accident medical specialists (rescuers, physicians, physiotherapists) want to have better equipment and medicines to provide their 
duties. Patients need better orthoses, prostheses, better approach to the facilities, better movement along the streets [4].

All above mentioned improvements in ordinary life, in production and transport, in exercises and sports, in medical procedures are the core engagement of engineering. Engineering process takes into account: a) idea of new device, which can be a result of thinking of a creator or can be an answer to the current needs of people; b) design of new products; c) materials of which a product will be built; d) energy, facility, and manpower that will be needed for production; e) construction and testing of models, sometimes smaller and sometimes larger than the future original; f) construction and testing the real product (a prototype); g) elaboration of mass production-tools, machines, assembly lines, robotization, energy sources; h) elaboration of instruction manuals and exploitation, workshops for conservation and fixing, utilization [5]. Medicine is a large area of interests of many people. One can say everybody in some period of his or her life was, is, or will be in contact with medicine. Some people say if somebody declares he or she is healthy, it means he or she has had no sufficient medical examination. Medical procedure encompasses: a) rescue and emergency procedures, b) diagnosis, c) therapy, d) rehabilitation, e) sanatory (convalescent house) care, f) elaboration of prophylaxis warnings. One of the most often needed medical branches is orthopedy. After orthopaedic activities comes a process of rehabilitation.

\section{Medical Devices in Orthopaedics and Rehabilitation}

\section{Orthopaedics devices}

Movement (musculoskeletal) system is very important for humans. It is a system for support, locomotion, defence, fight, for home and professional work. Its disability is an important problem for patients. Orthopaedics and rheumatology which cure movement system are present at the hospitals on a large scale. Around $1 / 3$ of hospital's beds are occupied by orthopaedics patients. Orthopaedics is one of the oldest branches of medicine. Some of orthopaedics' disorders are as follows: sprain, dislocation of a joint, fracture (partial or complete break in the bone-open or closed), abnormal vertebral column curvatures (excess of kyphosis or lordosis, presence of scoliosis), pains of different parts of musculoskeletal system, of both soft and hard tissues. Orthopaedics encompasses several disorders: congenital and developmental defects, deformation and disfunctions, degenerations, other systems diseases influencing musculoskeletal system, inflammations, cancer, effects of injuries [6,7]. There are a lot of presence of engineering within orthopaedics. The most simple approach to the injured patients is using of bandage, sling, orthopaedics rail, plaster of Paris, traction appliance. Orthopaedic devices can be divided onto diagnostic and modelling devices (Figure 1), surgery devices including those necessary for conducting of operation and those implanted into the patient's body, like: plates, rods, frames, hooks, nails, screws for stabilization of broken or deformed bones (Figures 2 \& 3). There are also distractors (Ilizarov device) for bone lengthening, several implants substituting especially joints and vertebrae (Figure 4).

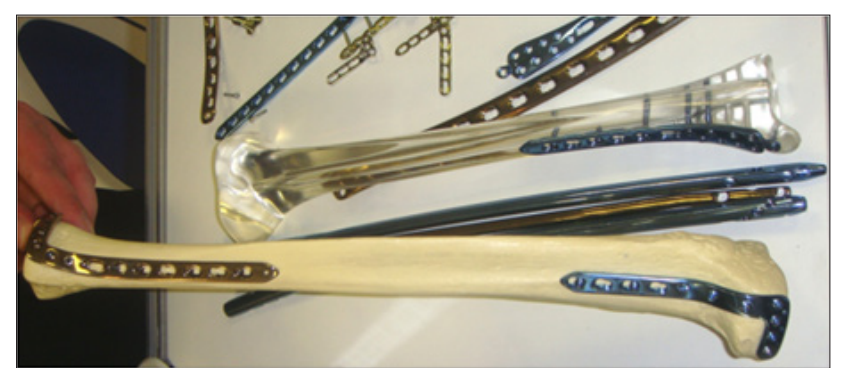

Figure 1: Artificial and real bones as models for surgery operation.

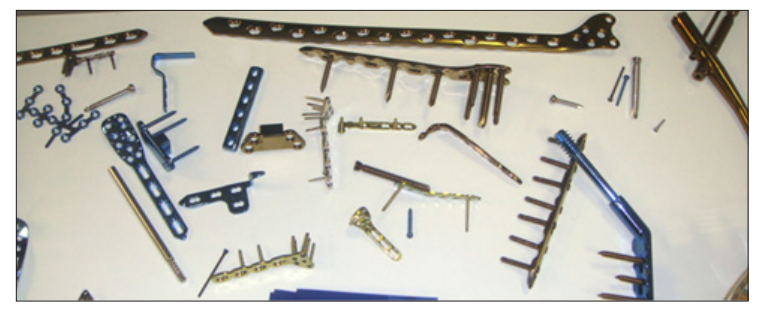

Figure 2: Surgery devices for orthopedic operation: plates, nails, screws.

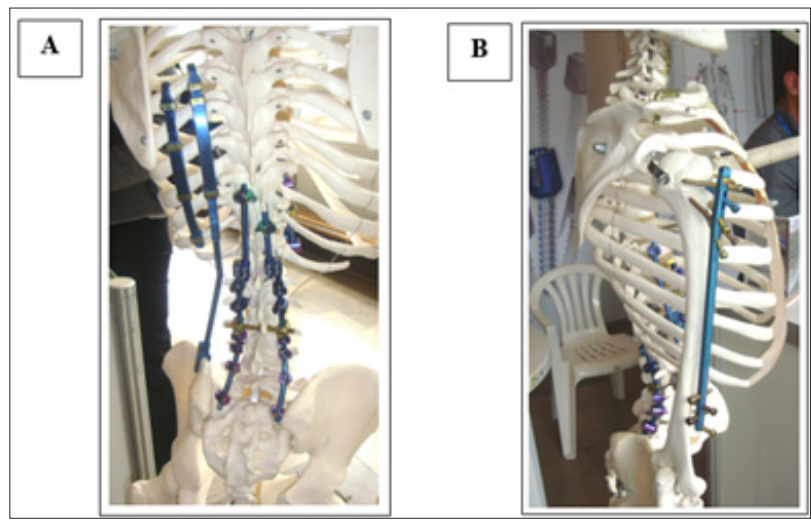

Figure 3: Surgery devices: A-Plates for reinforcement of vertebral column and ribs; B-Reinforcement of humerus bone.

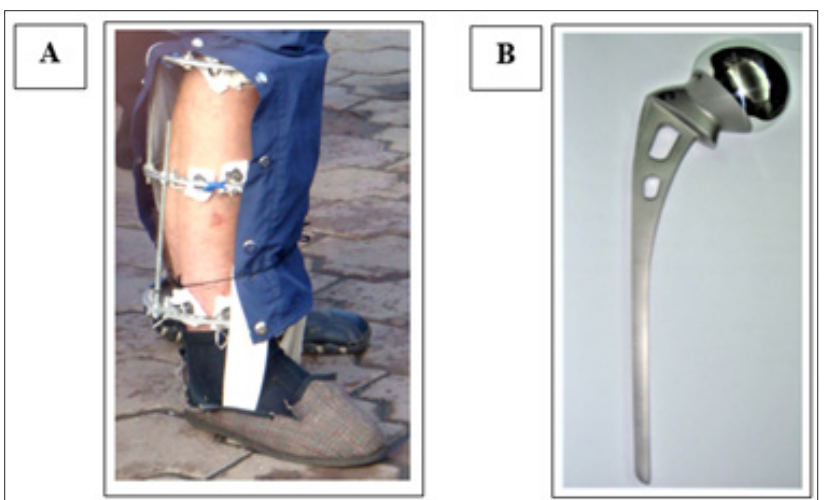

Figure 4: Surgery devices: A-Ilizarov device for lengthening of the shank bones; B-Implant of the proximal part of femur bone being part of the hip joint. 
Special engineering devices in orthopaedic procedure are orthoses and prostheses. Orthoses are devices which support weak or injured body part, especially joints. They are used especially for upper extremity's wrist and elbow joints and for lower extremity's ankle and knee joints (Figure 5A). Some orthoses like bands or wide belts are used for external stabilization of the trunk. They are used when a patient feels discomfort or is after vertebral column surgery (Figure 5B). Prostheses are devices that substitute lost parts of the body, especially those which are needed for locomotion. Another prostheses concern e.g. cardiovascular system. Those for skeletal system concern especially extremities-full extremities or their parts. Taking into account lower extremity they can be made for those with the loss of the whole lower extremity, for those with above or below knee amputation, those with foot loss (Figure 6). Similar is for upper extremity.

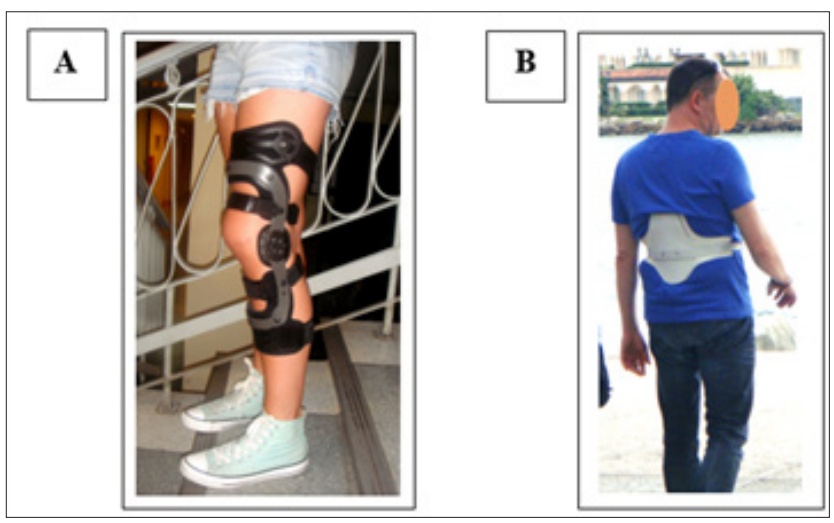

Figure 5: Orthopedics orthoses: A-For the knee joint; B-For lumbar part of the trunk.

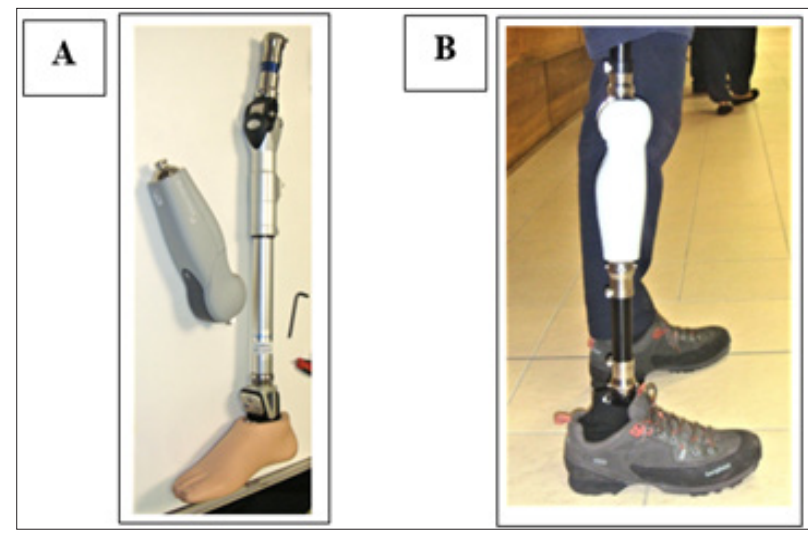

Figure 6: Orthopedics prosthesis for above knee amputation: A-Before; B-After set-up.

\section{Medical Rehabilitation}

Rehabilitation is a third, after diagnosis and therapy, aspect of medicine. General medical rehabilitation is a complex activity aimed towards regaining by the patient whole, or the maximum in the given state, body and mental fitness, work possibilities and social acceptance. Medical rehabilitation concerns both medical and social aspects. It aims to secure people with disability good level of life despite their lower level of physical possibilities. Medical rehabilitation appeared within the developed societies as an answer to war or natural disasters, congenital cripplehood, accidents. The word "rehabilitation" was introduced in 1918 by Douglas McMurtie from the American Red Cross when he described disabled soldiers after the World War. At first, this was labour rehabilitation, i.e., possibility of former injured soldiers to have professional work [8]. After the Second World War rehabilitation was included into the list of medical specialties. The aim was to restore physical abilities of patients concerning their body. In this view very important role was assigned to the physiotherapists, i.e., specialists of therapy through the movement (kinesitherapy), physical influence on the body through electricity, light, magnetism, warm fluids, minerals. Long time ago people knew that physical exercises or mineral warm waters were helpful in maintaining health and physical fitness. The same was applied to people with physical disabilities. In the modern times physicians from France, Sweden proposed exercises and devices for them. Such devices (bench, rope, ball) are used still in the modern times together with more sophisticated equipment. There are several forms of basic and advanced physical activity for people with disability. They include: a) basic body exercises, b) body exercises with equipment, c) body exercises using indoor and outdoor facilities, d) sport activities, e) competitive sport activities, f) Paralympics. Usually, at the beginning patients start individual exercises with the help of an instructor. He or she is moving patient's body parts performing passive exercises, i.e., patients with the help of instructor's gains muscle strength. After several weeks or even months a patient is able to perform exercises using his or her own muscles and to overcome external load (friction, springs, weights)-(Figure 7). Kinesitherapeutic exercises can be performed also within a swimming pool specially designed for people with disabilities (Figure $8 \mathrm{~A}$ ) or outdoor within the special fitness park (Figure 8B). Mechanical influence (mechanotherapy) is obtained also through massage using special equipment (air pump producing sequential pushing onto the muscles) or using water poured from a hydro-pump. There is also electro-mechanical saddle resembling that using for horses. This is used for small children in order to acquaintance them with the future real horse (hippotherapy).

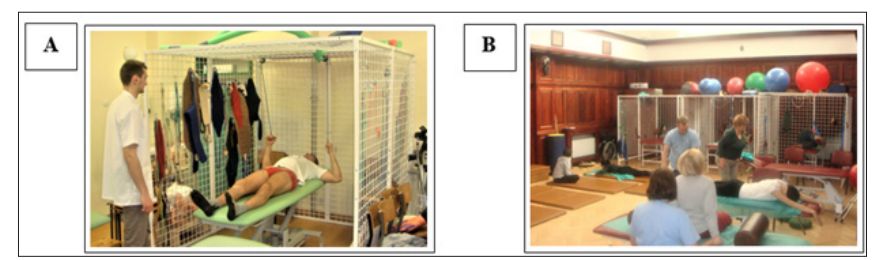

Figure 7: Examples of exercises using simple equipment: A-Individual exercises inside a special box performed alone only with the presence of an instructor; B-Individual exercises among the group alone or with the help of instructors. 


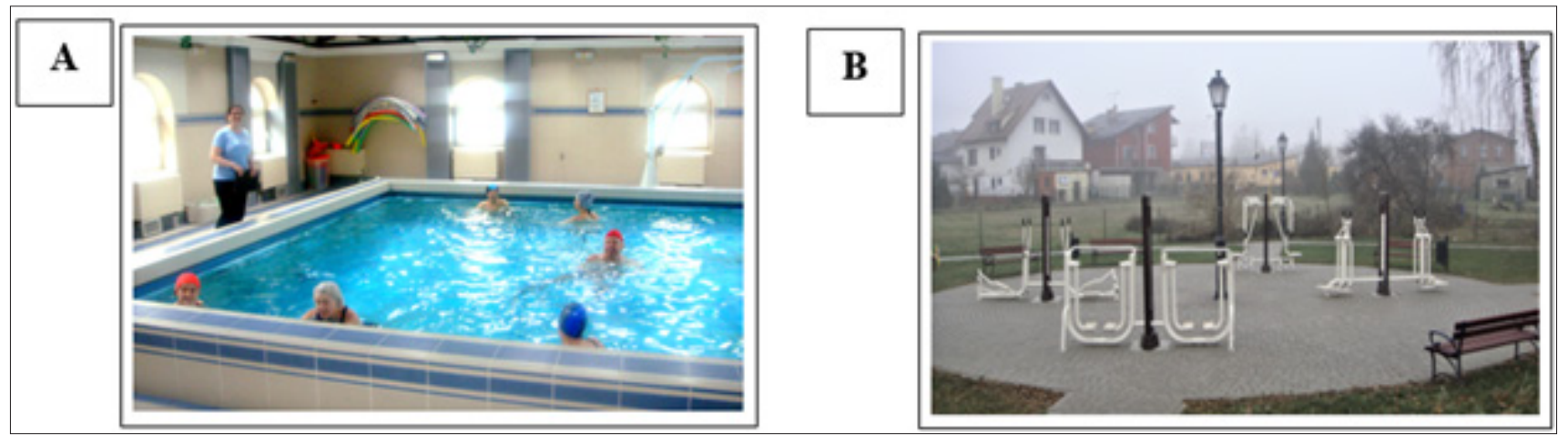

Figure 8: Examples of exercises at special environment: A-Individual or group exercises inside a swimming pool with the presence of an instructor; B-Fitness park for people with disabilities who can perform exercises without the help of an instructor.

Another engineering assistance is present within the physical therapy as a part of physiotherapy. Here, electrical current is used for stimulation of muscles in order to obtain their contraction. Electricity is also used for pain therapy, improvement of blood circulation, and other applications. Light is used in a form of ultraviolet spectrum of light. This is used for example for children who were out of the sun rays (production of vitamin D), for skin diseases (it fights skin bacteria). Also concentrated light (laser) is used for therapy in a form of continuous or impulse light. Sound has also therapeutic characteristics (sonotherapy). Here, for example ultrasound is used for obtaining images of the inside of the body (ultrasonography). Sonotherapy is used also for the pain of soft tissues, for striking bile stones, or as an artistic music. Thermotherapy is very useful in joint or muscle pains (diathermia). Also, sauna is practical in bad feeling of people. Advanced technical assistance for people with disability are manipulators and robots. Their role is to assist in physical impairments which affect patients' skills [9]. Present-day manipulators are robotisized or as fragments of robots. Constructors of modern manipulators say that hand without touch sensing is not a hand. The newest designs of hand manipulators, e.g., Perception Palm, include 6-axis force/torque sensor, fingertip torque sensors, and tactile sensing. In addition, it has two CMOS video cameras, a laser projector, an infrared rangefinder, LED illumination [10]. In reverse, devices that are touched need to be sensitive to human or machine touch [11]. Very important field of rehabilitation is sport for all and competitive sport. Here special equipment is present in order to use it by individuals with disability. There are wheelchairs, handbikes, sledges, monoskis, rowing boats and other specially designed equipment (Figure 9).
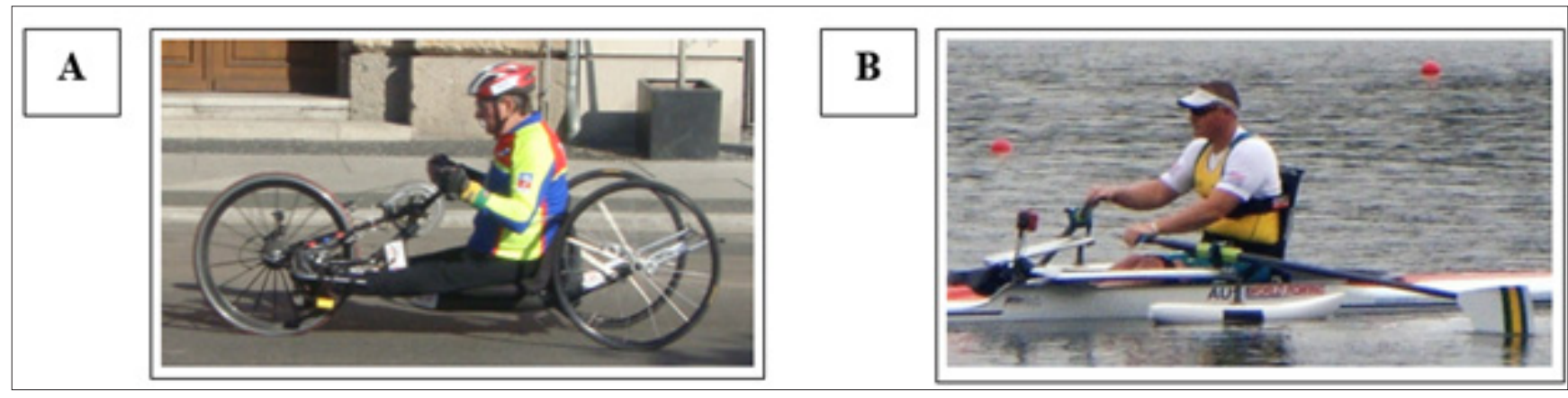

Figure 9: Participants at the sports for people with disability using: A-Hand bike; B-Rowing boat.

Another advanced approach to people with disability introduced Robert Riener from the Swiss Federal Polytechnic in Zurich [12,13]. In 2016 he organized “Cybathlon”. i.e., a competition where engineering was involved in a higher level (Figure 10). There were six disciplines during the event: 1) Powered Arms (Upper Extremities) Prostheses Race, 2) Powered Leg (Lower Extremities)
Prostheses Race, 3) Functional Electrical Stimulation Bike Race, 4) Powered Wheelchair Race, 5) Powered Exoskeleton Race, 6) BrainComputer Interface Race. The tasks were chosen not from sports for able-bodied competitors but rather from everyday living tasks, such as walking on uneven surfaces, stair climbing, opening and closing doors, and other tasks [1]. 


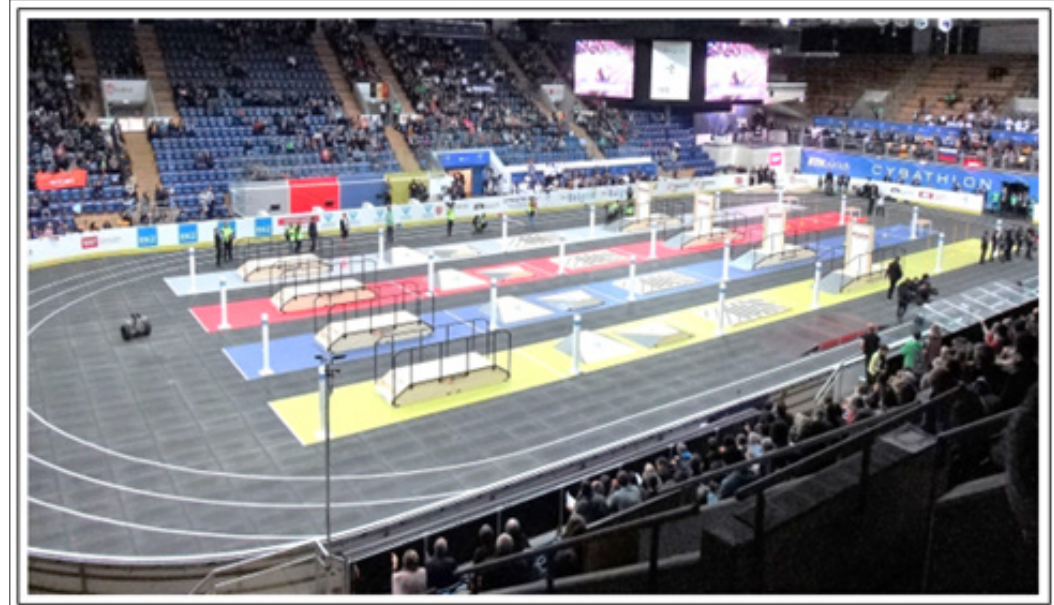

Figure 10: General view of the arena of the first "Cybathlon" in Zurich in 2016. The start of four lanes was at the right hand side and the finish was at the left hand side.

\section{Future Considerations}

With the development of technology, including faster cars and motorcycles, more and more people moving to several places of the world for exploration, more aggressive sport involvement or overloading of sportspeople through too many competitions, there will be more and more accidents and people with disabilities. There is a lack of sufficient number of specialists in many medical professions, including orthopaedics and rehabilitation. In some cases, for example in Poland, people are waiting for physiotherapy for several months. There is a need for further improvement in safety of people in many professions and in leisure time. There is also a need for more instructions for people with disabilities together with more free fitness parks in order people would use them for individual exercises.

\section{References}

1. (2016) Kasielke N (Ed.), Program/ Programs Cybathlon. Swiss Arena Kloten, Switzerland.

2. Bedzinski R, Scigala K (2011) Engineering biomechanics-fundamental problems and directions of development. In: Bedzinski R (Ed.), Biomechanics, In a serie: Gutkowski W, Technical mechanics, Committee of Mechanics and Institute of Fundamental Problems of Technology, Polish Academy of Sciences, Warsaw, Poland, pp: 21-76.

3. (2020) Disability inclusion. Worldbank, USA.
4. Erdmann WS (2015) Biomechanics. Basis for biomedical engineering major.

5. Erdmann WS (2016) Engineering of movement rehabilitation.

6. Dega W (1983) Orthopedics and rehabilitation in contemporary formulation. In: Dega W (Ed.), Orthopedics and rehabilitation, $\left(3^{\text {rd }}\right.$ edn), State Publisher of Medical Publications, Warsaw, Poland, pp: 9-16.

7. Bieniek T, Cholewinski J, Cielinski L (2009) Compendium of orthopedics.

8. Milanowska K (1983) History of rehabilitation development. In: Dega W, Milanowska K (Eds.), Medical rehabilitation. Warsaw: State Publisher of Medical Publications, Poland, pp: 1-7.

9. Morecki A (1999) Rehabilitation manipulators. In: Morecki A, Knapczyk J (Eds.), Basic of robotics: theory and components of manipulators and robots. CISM International Center of Mechanical Sciences: Course and lectures, Springer, Europe, pp: 433-461.

10. Barret G (2019) Multi-fingered programmable grasper.

11. Barrett G, Omote R (2009) Projected-capacitive touch technology. Information Display 3(10):16-21.

12. Riener R (2016a) The cybathlon promotes the development of assistive technology for people with physical disabilities. J Neuro Eng Rehab 13: $1-4$.

13. Riener R (2016b) Technology for Everyday Life. In: Kasielke N (Ed.), Programm/Programme Cybathlon, Swiss Arena Kloten, Swiss Federal Polytechnic, Zurich, Switzerland. 